\title{
OBSERVATIONS
}

on

SOME PECULIARITIES

or

\section{POLYPUS OF THE UTERUS.}

\author{
BY CHARLES LOCOCK, M.D., \\ FIRST PHYSICIAN-ACCOUCHEUR TO THE QUEEN, \\ PHYSICIAN EXTRAORDINARY TO THE QUEEN-DOWAGER, \\ AND \\ CONSULTING PHYSICIAN TO THE GENERAL LYING-IN hOSPITAL.
}

Received March 24th-Read April 25th, 1848.

UPWARDS of twenty years ago, the late Dr. Robert Hooper showed me a preparation of a uterus, laid open, having a polypus not larger than a pea, with a short and narrow peduncle, attached within the cervix, high up, considerably within the os uteri, and not perceptible till the cervix was slit open. All the history which he could give me was, that the uterus was removed from the body of a young woman, who had died in the Marylebone Infirmary, from long-continued uterine hæmorrhage. The preparation was removed to the Museum of St. Thomas's Hospital, and is probably there still.

Several years after this, I was consulted by a medical friend about his own wife, who had had a large family, but was then suffering from frequent attacks of profuse uterine hæmorrhage. On examining the uterus, my first impression was, that there was nothing else discoverable but a relaxed condition of the organ; but finding the os uteri a little dilated, I passed a finger through it, and I distinctly felt the tip of a very small polypus, considerably within the cervix. It appeared impossible to remove a polypus, in such a situation and of so small a size, and I prescribed nothing beyond the ordi- 
nary means to restrain the hæmorrhage, hoping that in time the polypus would become larger and more within reach. The patient went out of town for the summer months, but some weeks afterwards I received intelligence that the hæmorrhage had been alarmingly profuse, and the vital powers were much reduced. I advised repeated doses of the ergot of rye, hoping that by such a medicine the polypus might be brought more within the reach of instruments. The next night I went down to the neighbourhood of Rochester to see the lady, taking with me the necessary apparatus for removing the polypus, if possible.

I found her with a bloodless countenance, and a most feeble flickering pulse, and it seemed evident that if the hæmorrhage continued, she could not much longer survive. The ergot appeared to have had some effect upon the os uteri, which was thinner and more dilatable, but the polypus was scarcely more within reach than before, and all attempts to catch hold of it by forceps or hooks entirely failed. The only plan I could think of was gradually to pick off or dig through the polypus with my finger nail, and by perseverance I gradually succeeded : the patient perfectly recovered, and had another child a year afterwards.

I have since met with four cases of a similar character, where the polypus was equally small, and situated, in like manner, quite within the os uteri, attached to the cervix, one by a small peduncle, but the others with an attachment nearly as broad as the growth itself.

There is one fact connected with their detection which is worthy of notice. I never discovered the polypus in these cases, when I examined the uterus in the intervals between the attacks of hæmorrhage, either by the finger or the speculum. The os uteri was closed, the uterus having its natural feel, and I could detect nothing locally to account for the hæmorrhage. In the first of these cases, after I had made the examination in which $I$ had detected nothing, I was sent for subsequently on account of the immediate alarm from the profuseness of the loss of blood, which was so excessive 
that I was induced to plug the vagina. On removing the plug on the following day, I again examined the uterus, and finding then the os uteri more open and flaccid, I passed my finger through it, and discovered the polypus.

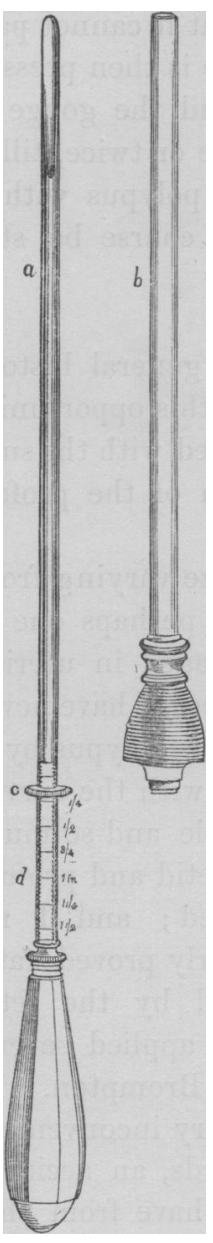

In the other cases, it was only by examining during the attacks of hæmorrhage that I was able to discover the small polypus that existed, as no vestige of it was perceptible after the os uteri had again closed, in the intervals of the attacks.

It was with exceeding difficulty, and after many failures, that I was enabled to remove the small polypi in three of these cases. I succeeded best by passing a stick of nitrate of silver (concealed in a canula, and made to slide out) through the os uteri up to the polypus, and holding it there for several seconds ; but many successive applications were necessary, though very little pain or subsequent disturbance resulted. I often felt that if I had a finger-nail long enough, strong enough, and sharp enough, I might scoop away the polypus, as I had done in the case of my medical friend's wife, near Rochester. I therefore had an instrument made* (see figure), which acts on that principle, and which $I$ have tried in the most recent of $\mathrm{my}$ cases, and found that with it I could easily and expeditiously cut away the morbid growth. It is simply a very small, fine, and sharp scoop $(a)$, like a carpenter's gouge, inclosed in a canula (b), either to remain entirely within, or made to protrude beyond the sheath; the length of the protrusion being regulated by a screw $(c)$ at the handle $(d)$, which is graduated in quarters

* The instrument was made by Savigny, St. James's-street. 
of an inch to the extent of an inch and a half. The gouge is passed through the os uteri up to the root of the polypus, still concealed in the canula: it is then pushed beyond the confines of the enclosing tube, for about a quarter of an inch, care being taken, by means of the screw, that it cannot pass beyond the desired length. The cutting edge is then pressed steadily against the base of the polypus, and the gouge is worked gently half round and back again once or twice, till it has cut through the object. In cases of polypus with a very small peduncle, the operation would of course be still more easy.

Without any intention to enter upon the general history or treatment of polypus of the uterus, I take this opportunity of noticing one or two circumstances connected with the subject, that I think deserving of the attention of the profession.

An ordinary polypus of the uterus, of a size varying from that of a hazel-nut to that of a large pear, is perhaps one of the simplest cases and the most easily managed in uterine surgery. For many years, in all such instances, I have never used the ligature, preferring to draw down the polypus by a pair of double hook forceps, and to excise it with the curved scissors or a bistoury. By this plan, so simple and so much more expeditious, all the mischief from the fetid and profuse discharges incident to the ligature is avoided; and I remember to have seen a case which very nearly proved fatal from the constitutional disturbance caused by the fetid matters poured out after a ligature had been applied several days, in the practice of the late Mr. Glen, of Brompton. In one instance of excision, my patient lost a very inconvenient quantity of blood, for several hours afterwards, an accident which has never since occurred to me, as $I$ have from that time followed a suggestion of Sir Benjamin Brodie's, and have taken care to produce torsion of the arteries previous to excision, by twisting the polypus round several times, after fixing the double hook forceps. 
In very large polypi, it may be safer perhaps to apply the ligature at first; but in two or three days, after the circulation through the polypus has been well strangulated, I have preferred to draw it down by means of the ligature, and then to cut through the neck above the noose. There are, however, cases beyond the reach of the scissors or the bistoury, where the polypus is so large and so blocks up the pelvis, that the neck cannot be felt. I have never yet met with one, however, where a ligature could not be applied, by passing it by means of the double canula of Niessens, as recommended by the late Dr. Gooch, high up in the pelvis, and even within the os uteri, till on tightening the cord it is felt to slip over the convexity and embrace the peduncle. The mere fact of not being able to feel the neck of the polypus or the os uteri, with the finger, is no insurmountable impediment to passing the ligature, although it often renders it exceedingly difficult, requiring much patience and careful management.

But there are cases which I have often found particularly troublesome, where instead of a polypus being too large for convenient removal, it is too small. These are instances where the polypi are easily to be distinguished by the touch, but are far too small to be noosed by a ligature, and often baffle the operator considerably, in attempting to seize them by the forceps or the hooks. I have lately found this difficulty vanish, by simply bringing them within sight, through a speculum, and for this purpose a bivalve speculum (Ricord's) is more convenient for subsequent manipulation, than a tubular one. I may here notice also, that in all the cases where I have thus brought a small polypus into view, whether they were attached to the os uteri or passed through it, they were of a dark red or purple colour, resembling a hæmorrhoid, and were perfectly different in hue from the neighbouring structure of the os uteri. When in full eyesight, nothing is more easy than to snip them off with a pair of curved scissors, with or without the assistance of the forceps, and I have usually afterwards touched the cut surface with the nitrate of silver. 
I may mention as a singular fact connected with the history of large polypi, that some months since I removed one from a patient of Mr. Baker's, Bulstrode-street, as large as a foetal head at seven months, where none of the usual symptoms of polypus had ever been noticed, neither hæmorrhage nor leucorrhœa, and where the polypus was discovered accidentally, from its pressure on the bladder leading to the necessity of the catheter.

Some of the observations I have thus ventured to submit to the Society have not, I believe, hitherto been publicly noticed, and may perhaps be worthy. of attention, as conveying a few hints that others may find serviceable in practice.

Postscript, June 15, 1848.-Since this paper was read before the Society, my attention has been directed to a most interesting and instructive publication on polypus by $\mathrm{Dr}$. Montgomery, in the Dublin Quarterly Journal for August 1846. The cases of very small polypi described by me, so far differ from those mentioned by Dr. Montgomery, that mine were quite out of sight and out of reach, except during the relaxed state of the os and cervix uteri during the actual attacks of hæmorrhage. In his description of the appearances and colour of the small polypi, and in his plan of using the speculum for the purpose of removing the growth, he has clearly anticipated me. 